\title{
Molecular Self-Assembly Versus Surface Restructuring During Calcite Dissolution
}

\author{
Martin Nalbach, Stefanie Klassen, Ralf Bechstein, and Angelika Kühnle* \\ Institute of Physical Chemistry, Johannes Gutenberg University Mainz, Duesbergweg 10-14, 55099 Mainz, Germany
}

Supporting Information

\begin{abstract}
Organic additives are known to alter the mineral-water interface in various ways. On the one hand, organic molecules can selfassemble into ordered structures wetting the surface. On the other hand, their presence can affect the interfacial morphology, referred to as surface restructuring. Here, we investigate the impact of a class of calciumcomplexing azo dyes on the dissolution of calcite (10.4) using high-resolution atomic force microscopy operated in aqueous solution, with a focus on the two constitutional isomers Eriochrome Black T and Eriochrome Black A. A very pronounced surface restructuring is observed in the presence of the dye solution, irrespective of the specific dye used and independent of the $\mathrm{pH}$.

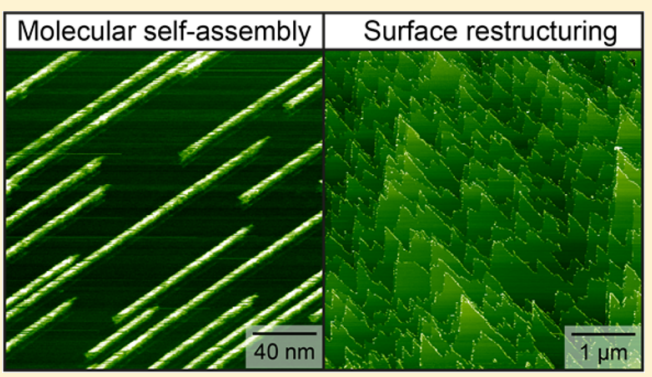
This surface restructuring is obtained by the stabilization of both the nonpolar acute and the polar [010] step edges, resulting in a greatly altered, characteristic interface morphology. In sharp contrast to the prevalence of the surface restructuring, an ordered molecular structure on the crystal terraces is observed only under very specific conditions. This formation of an ordered stripe-like molecular structure is obtained from Eriochrome Black A only and limited to a very narrow $\mathrm{pH}$ window at a $\mathrm{pH}$ value of around 3.6. Our results indicate that such molecular self-assembly requires a rather precise adjustment of the molecular properties including control of the conformation and deprotonation state. This is in sharp contrast to the additive-induced surface restructuring, which appears to be far more robust against both $\mathrm{pH}$ changes and variations in the molecular conformation.
\end{abstract}

\section{INTRODUCTION}

The interaction of organic molecules with mineral surfaces within their natural environment is decisive for a wide range of processes within fields such as geochemistry ${ }^{1-3}$ and biomineralization $^{4-7}$ as well as within industry. ${ }^{8,9}$ Especially calcite, the most stable polymorph of calcium carbonate, has attracted great attention due to its abundance in the earth crust and its pivotal role in the above-mentioned areas. ${ }^{10-21}$ Consequently, additive-induced changes of the calcite-water interface have been studied in an attempt to rationalize processes during biomineralization and biomimetic crystallization. ${ }^{21-27}$ To this end, microscopy techniques have been proven to provide highresolution insights into additive-controlled calcite dissolution, growth, and surface restructuring, as these techniques offer the ability to directly visualize the mineral-water interface ${ }^{28}$ as well as the hydration structure above the surface. ${ }^{20,29,30}$ This realspace insight is often combined with complementary experimental information, e.g., spectroscopic or X-ray reflectivity measurements, and theoretical investigations such as molecular dynamics simulations. ${ }^{31}$ However, despite considerable effort in this field, elucidating the detailed mode-ofaction of organic additives in calcite nucleation, dissolution and growth remains a challenge in most cases. In this context, an interesting question addresses the competition between additive-induced surface restructuring ${ }^{21,23,32}$ and the formation of a self-assembled molecular structure ${ }^{33}$ on the mineral surface. ${ }^{19}$ While both processes can, in principle, occur at the same time, the vast majority of studies reported so far have revealed distinct surface restructuring, often resulting in the formation of otherwise thermodynamically unstable step edges, e.g., the polar [010] step edge. ${ }^{21}$ In contrast, reports on the formation of ordered, self-assembled molecular structures on the mineral surface are comparatively rare. On the one hand, this might be in part due to the fact that massive surface restructuring can be readily detected, while self-assembled structure might be more challenging to be observed as they require high-resolution techniques capable of monitoring a weakly bound molecular monolayer at the mineral-water interface. On the other hand, this observation could also be indicative of a more general principle at play during interaction of organic molecules with the mineral-water interface.

In this work, we investigate molecules from the class of Eriochrome azo dyes (Figure 1a,b), which are known to interact with magnesium and calcium ions as well as other diand trivalent metal ions as they are used for chelatometric titration. ${ }^{34-37}$ Stability constants of the magnesium and calcium complexes and their binding motives have been studied intensively using extinction experiments. ${ }^{34}$ Due to their complexation ability, the Eriochrome azo dyes, especially Eriochrome Black T, are therefore used to determine water

Received: July 20, 2016

Revised: August 30, 2016

Published: September 7, 2016 
(a) EBT

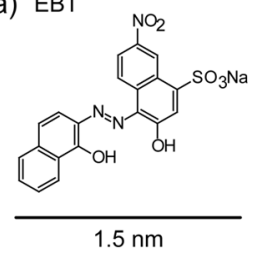

(b) EBA

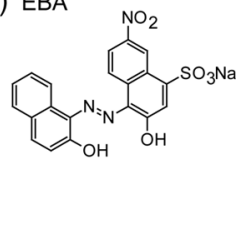

(c) Calcite $(10.4)$

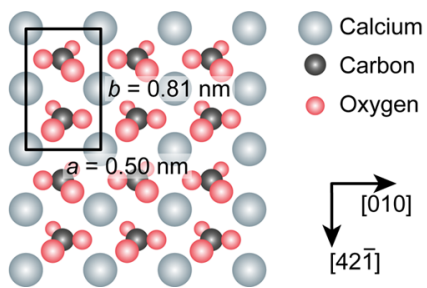

Figure 1. Model of the two constitutional isomers of the Eriochrome azo dyes, namely, (a) Eriochrome Black T (EBT) and (b) Eriochrome Black A (EBA), which are used for main body of experiments this study. (c) Model of the calcite (10.4) surface. The scale bar applies to both subfigures.

hardness. We demonstrate that the ability to restructure the (10.4) surface of calcite (Figure 1c) into a characteristic morphology appears to be a general property of these molecules, irrespective of the specific molecular structure and the solution $\mathrm{pH}$ value. By contrast, the formation of an ordered self-assembled structure is more delicate to achieve. We observe molecular self-assembled structures only for one out of the five Eriochrome dyes tested and only in a narrow $\mathrm{pH}$ window. Our work indicates that molecular self-assembly requires a precise tuning of the molecule's properties including control of conformation and deprotonation state, while surface restructuring appears to be more robust against variations in the molecular properties.

\section{EXPERIMENTAL SECTION}

Unless otherwise stated, all images shown here were taken using frequency modulation atomic force microscopy (FM-AFM) operated in liquid environment. High-resolution imaging in FM-AFM mode in liquids is enabled by rigorous noise reduction, ${ }^{38}$ providing true atomic resolution on a routine basis. Moreover, to avoid problems associated with the so-called "forest of peaks" 39 in the resonance spectrum, we have implemented photothermal excitation. ${ }^{40}$ The scan directions and the displayed channel are given in the schematics in the upper right corner of each image.

The images were taken in a closed liquid cell (Bruker Nano Surface Devision) at a constant temperature of $28{ }^{\circ} \mathrm{C}$ with gold-coated p- doped silicon cantilevers (PPP-NCHAuD, Nanosensors), having typical spring constant of $42 \mathrm{~N} / \mathrm{m}$, an eigenfrequency of $150 \mathrm{kHz}$, and a quality factor of $8-10$ in water. The amplitude of the cantilever oscillation was kept constant at $1 \mathrm{~nm}$ for all measurements.

The Eriochrome Black azo dyes Eriochrome Black T (EBT), Eriochrome Black A (EBA), Eriochrome Blue Black B (EBBB), Eriochrome Blue Black R (EBBR) and Eriochrome Red B (ERB) were purchased from Sigma-Aldrich and TCI Deutschland GmbH and used without further purification (for further details, see Supporting Information). For water deionization we used a purification setup from Millipore (Millipore $\mathrm{GmbH}$ ). To adjust the initial $\mathrm{pH}$ of the solutions, standard solutions of $\mathrm{NaOH}(0.1 \mathrm{~N})$ and $\mathrm{HCl}(0.1 \mathrm{~N})$ were purchased from Carl Roth. $\mathrm{pH}$ measurements of the dye solutions were conducted using a Schott laboratory pH meter (CG 842) equipped with a BlueLine $\mathrm{pH}$ electrode (Schott Instruments, $18 \mathrm{pH}$ ). Prior injection into the closed liquid cell using a syringe, the temperature of the measuring solutions was stabilized to $28{ }^{\circ} \mathrm{C}$. For each experiment freshly cleaved calcite crystal (Korth Kristalle $\mathrm{GmbH}$ ) were used, and one to three different positions were examined.

\section{RESULTS AND DISCUSSION}

To assess the impact of the class of Eriochrome Black molecules on the calcite-water interface, we performed in situ solution exchange experiments as shown in Figure 2. Here, the etch pits characteristic for calcite (10.4) are revealed in the absence of the additive molecules (Figure $2 \mathrm{a}$ ). These etch pits are characterized by a rhombohedral shape with the two acute step edges being straight, while the obtuse step edges are known to develop into curved steps. ${ }^{10,41-43}$ Upon exchange of the water by a $0.14 \mathrm{mM}$ EBT solution, the surface is observed to restructure. Already $46 \mathrm{~min}$ after injection of the molecules, the acute step edges appear to be decorated by molecules, while the obtuse step edges seem less covered Figure $2 \mathrm{~b}$. In the course of the experiment, the obtuse step edges vanish, and steps along the [010] direction appear instead (Figure 2c). These newly formed steps in the [010] direction are found to be decorated with molecules. Overall, a characteristic triangularshaped terrace termination emerges from this restructuring (Figure 2d).

A model for the observed step edges in the absence and presence of EBT is given in Figure 3. The characteristic edge pits in the absence of molecules are terminated by two steps running in the [441] and [481] directions (Figure 3a). All four step edges have in common that they are neutral with an alternating arrangement of calcium ions and carbonate groups (Figure $3 b$ ). However, the edges differ due to the tilt in the carbonate groups, resulting in acute and obtuse edges, as indicated by the unit cell symbol in the lower left corner of Figure $3 \mathrm{a}$. The edge pit termination at the two obtuse sides are
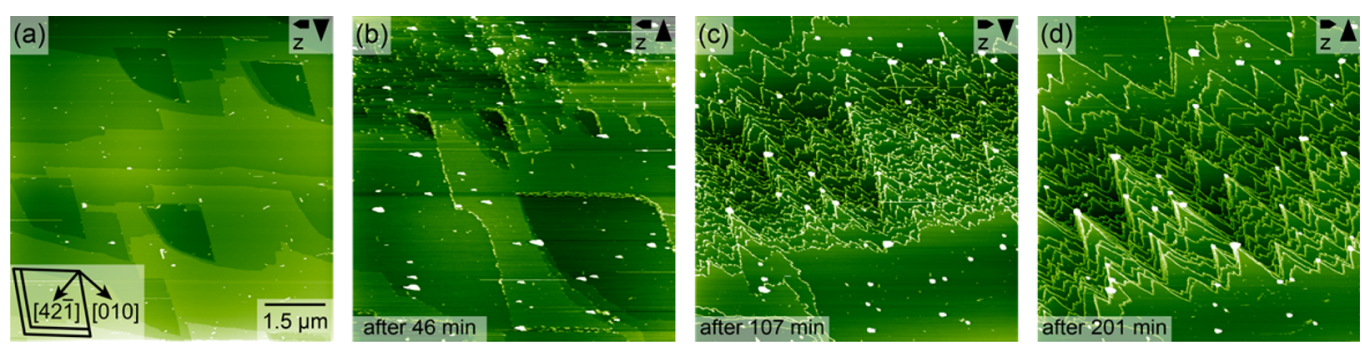

Figure 2. In situ solution exchange experiment demonstrating the additive-induced changes in the calcite surface morphology upon adding EBT to the solution. Image $a$ is taken before exchanging the deionized water by a $0.14 \mathrm{mM}$ solution of EBT with an initial $\mathrm{pH}$ value of 3.6 . Images $\mathrm{b}$, c, and $\mathrm{d}$ were taken 46, 107, and $201 \mathrm{~min}$ after the addition of EBT. The scale bar in image a applies to all images in this series. After molecule addition, large bright features appear on the surface as can be seen in image $b$. These features remain on the surface after the restructuring and appear to constitute the terminating sites at the tip of the triangular-shaped terraces. 

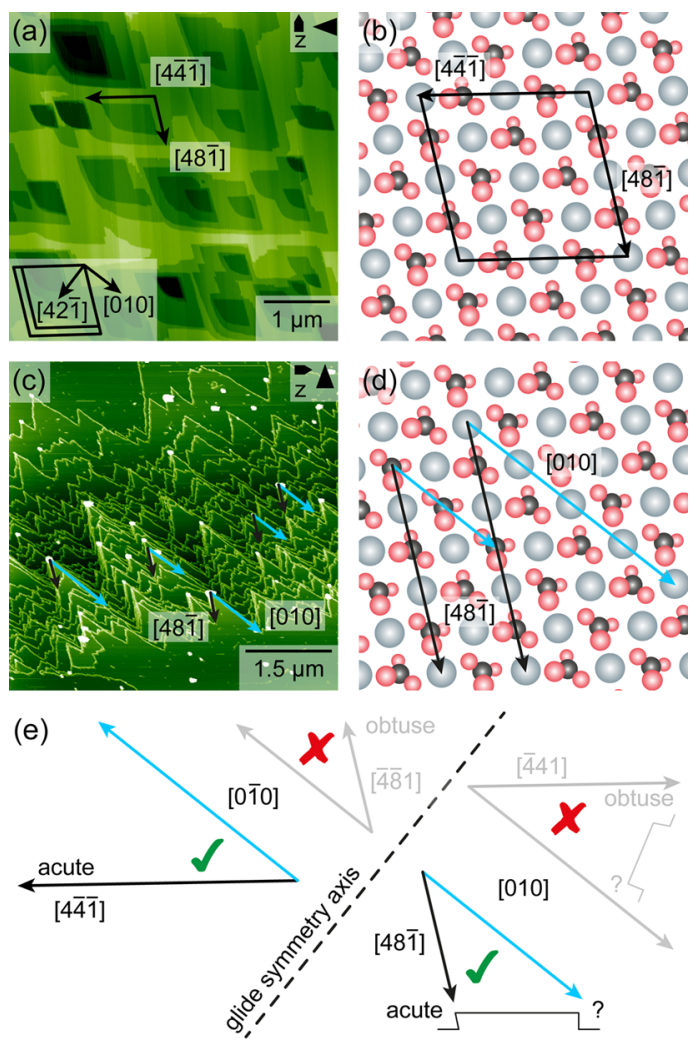

Figure 3. Model for the observed step edges in the absence and presence of EBT. (a) Amplitude modulation AFM image of the bare calcite (10.4) surface, exhibiting the characteristic rhombohedral etch pits. The obtuse step edges are known to exhibit a curved shape $^{10,41-43}$ (b) Model of the calcite (10.4) surface showing the thermodynamically most stable step edges that terminate the etch pits, running along the [4ㄴ1]] and [481] directions. (c) Surface morphology in the presence of $0.14 \mathrm{mM}$ EBT. Triangular-shaped terrace terminations are formed. (d) Model of the surface indicating the two predominant directions marked with black and blue arrows in (c). The step edge marked in black is the originally existing acute step edge in the [481] direction. The direction marked in blue is the [010] direction. Steps in this direction are polar because they are terminated by either calcium or carbonate groups exclusively. (e) Model illustrating the different terrace terminations and the glide reflection symmetry of the surface.

known to develop into a rounded shape, resulting in an asymmetric etch pit appearance. ${ }^{10,41-43}$
An image showing the characteristic triangular-shaped terrace terminations in the presence of EBT is given in Figure $3 c$ with the corresponding surface model in Figure $3 \mathrm{~d}$. While the acute step edge running along the [481] substrate direction is still present in this image, all other edges of the edge pit have vanished. Instead, new edges are obtained that run along the [010] direction. Steps in the [010] direction are characterized by the fact that they are formed either by calcium ions or by carbonate groups exclusively. Thus, these step edges are polar. Both, the acute, nonpolar steps along the [481] direction and the polar steps along the [010] direction are observed to be decorated by molecules. Due to the glide reflection symmetry of the surface with the glide reflection axis along the [421] direction, an equivalent situation is obtained when step edges along the acute [441] and the [010] direction are formed, resulting in the very same triangular-shaped termination of the terraces (Figure 3e). This situation is, indeed, equally observed experimentally (not shown here).

Thus, the presence of the EBT molecules appears to stabilize both the acute nonpolar edges as well as the polar edges along [010]. Interestingly, the obtuse edges are not stabilized by the presence of the EBT molecules and, thus, vanish in the course of the experiment in favor for the polar edges along the [010] direction.

To obtain further insights into the step edge decoration, we performed high-resolution images directly at a step. As shown in Figure $4 \mathrm{a}$, the step edge decoration is not limited to a single molecular row, but is imaged as a broad stripe with an apparent width of several tens of nanometers and an apparent height of $1-2 \mathrm{~nm}$, as can be deduced from the line profile given in Figure 4b. No internal order can be resolved within the molecular stripe. A further zoom onto the molecular stripe and the calcite substrate as shown in Figure $4 c$ reveals atomic resolution of the underlying calcite lattice. This high resolution is indicative of a sharp tip termination. Despite the good tip quality, no further structure could be resolve in the molecular stripe, suggesting a poorly ordered molecular stripe or rapidly moving end groups rather than a rigid and ordered molecular structure at the edges.

Next, we investigated the $\mathrm{pH}$ dependence of the observed additive-induced surface restructuring. Changing the $\mathrm{pH}$ of the solution changes the deprotonation state of EBT. In Figure 5a, the species distribution is given as a function of the $\mathrm{pH}$ value of the solution (for further details, see Supporting Information). While one-fold deprotonated molecules are the dominant species at a $\mathrm{pH}$ around 3-4, the dominant species at a $\mathrm{pH}$ value around 9 is two-fold deprotonated. At a $\mathrm{pH}$ of 6.3, the one-fold
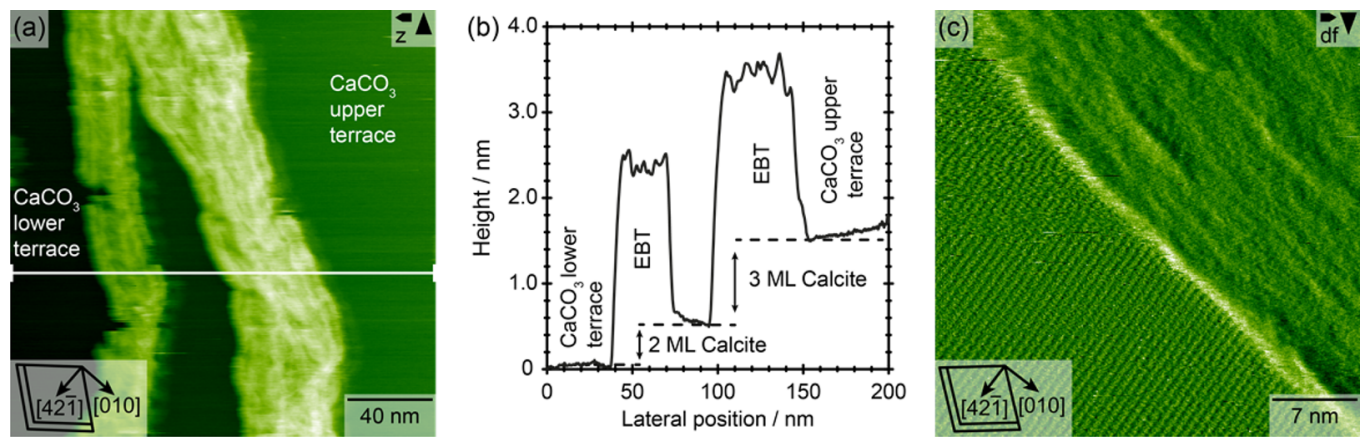

Figure 4. Step edge termination in the presence of EBT. (a) Zoom onto a step edge highlighting the molecule-covered step edges. (b) Line profile taken at the indicated position in image a, revealing an apparent height of the molecular structure of $1-2 \mathrm{~nm}$. (c) Zoom onto the boundary of the molecular structure and the bare calcite, revealing atomic resolution on the calcite (10.4) surface (lower left part). 
(a)

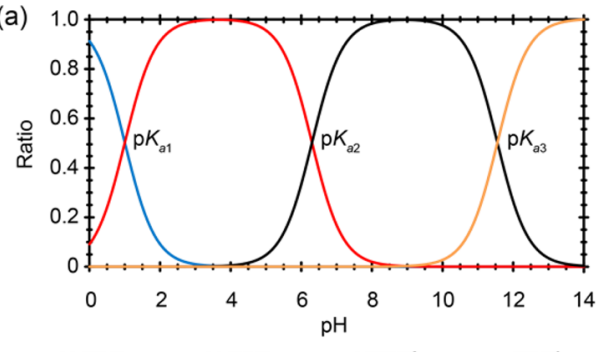

$-\mathrm{H}_{3} \mathrm{EBT}-\mathrm{H}_{2} \mathrm{EBT}^{-}-\mathrm{HEBT}^{2 \cdot}-\mathrm{EBT}^{3}$

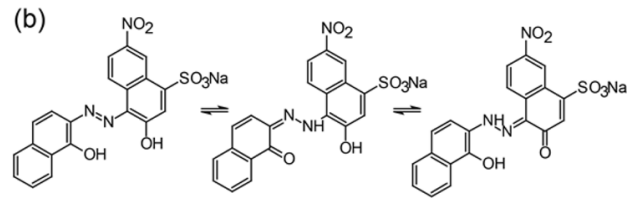

Figure 5. (a) Species distribution of EBT as a function of the $\mathrm{pH}$ value. (b) Azo-hydrazo tautomerization of a one-fold deprotonated EBT molecule.

and two-fold deprotonated species are equally present. Moreover, we note that EBT can undergo an azo-hydrazo tautomerization $^{44}$ (Figure $5 \mathrm{~b}$ ), resulting in three (four, one) different species for the one-fold (two-fold, three-fold) deprotonated molecule, respectively (see Supporting Information).

As demonstrated in Figure 6, the characteristic triangular terrace termination is found for all $\mathrm{pH}$ values tested here, ranging from a $\mathrm{pH}$ of 3.6 to 9.1. This fact indicates that the surface restructuring ability appears to be independent of the specific deprotonation state of the molecule.

Moreover, while we show the surface restructuring induced by EBT as a representative example, the very same surface morphology was revealed for all Eriochrome Black dyes studied here. Thus, the ability to restructure the surface into a characteristic morphology with triangular-shaped terrace terminations appears as a general property of the entire class of the Eriochrome Black dye family. The restructuring is insensitive against changes in the molecular conformer or even molecular structure. Moreover, the specific deprotonation state of the molecule seems not to affect the restructuration ability.

In sharp contrast to the prevalence of substrate restructuring, ordered self-assembled structures were observed only for one out of the five tested Eriochrome Black azo dyes, namely, EBA. As shown in Figure $7 \mathrm{a}$, the presence of EBA results in the characteristic triangular terrace termination as reported above. Interestingly, when zooming into a terrace, molecular rows are
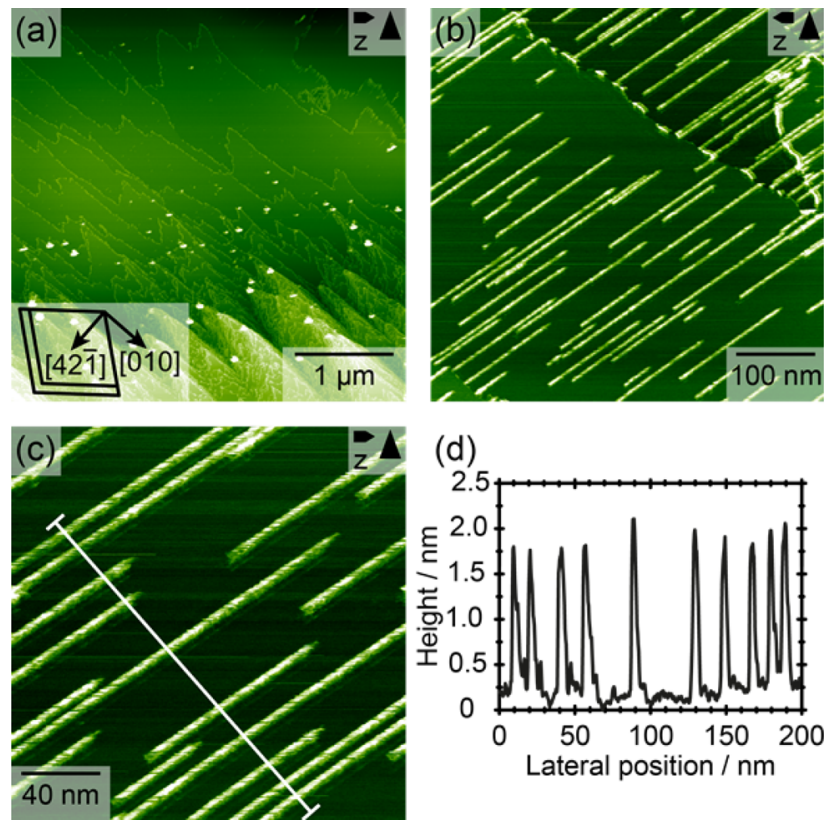

Figure 7. Coexistence of surface restructuring and molecular selfassembly induced by addition of $0.16 \mathrm{mM} \mathrm{EBA}$ solution at anitial $\mathrm{pH}$ value of 3.6. (a) Large-scale image illustrating the characteristic surface restructuring. (b) Zoom onto a calcite (10.4) terrace, revealing unidirectional rows. (c) Further zoom onto the molecular rows with position marked of the line profile shown in panel $d$.

observed that run along the [421] substrate direction (Figure $7 \mathrm{~b})$. A line profile taken at the position indicated in Figure $7 \mathrm{c}$ reveals an apparent height of about $1.5 \mathrm{~nm}$ (Figure $7 \mathrm{~d}$ ). The width of the stripes is uniform, indicating a highly ordered molecular structure. Most importantly, these stripes were only observed for an initial $\mathrm{pH}$ value of the solution of 3.6, not for the solution with initial $\mathrm{pH}$ value of 6.3 nor 9.1. From this we conclude that the formation of an ordered self-assembled structure requires precise control of the molecular deprotonation state. Apparently, only the one-fold deprotonated EBA species can form a self-assembled structure on the calcite (10.4) terrace. Moreover, EBT, which is a conformational isomer of EBA, does not exhibit these rows. Thus, also the conformational structure is decisive for the formation of the selfassembled rows.

A detailed discussion of the observed prevalence of moleculeinduced surface restructuring in contrast to molecular selfassembly requires a quantitative analysis of all involved interactions, which is beyond the scope of this work. A
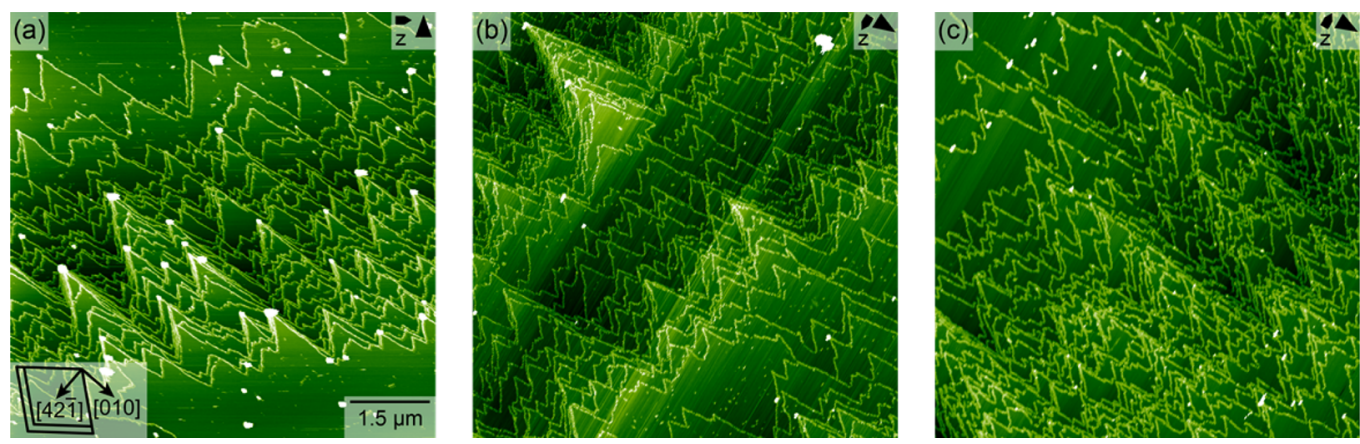

Figure 6. Demonstration of the $\mathrm{pH}$ independence of surface restructuring by EBT. Calcite (10.4) surface in the presence of $0.11-0.14 \mathrm{mM}$ EBT at an initial solution $\mathrm{pH}$ of (a) 3.6, (b) 6.3 and (c) 9.1. The scale bar in image a applies to all images in this series. 
qualitative statement can, however, be made to identify the main mechanism responsible for this observation. The resulting equilibrium structure arises from a competition of all involved interactions (Figure 8). In solution, the water-soluble molecules

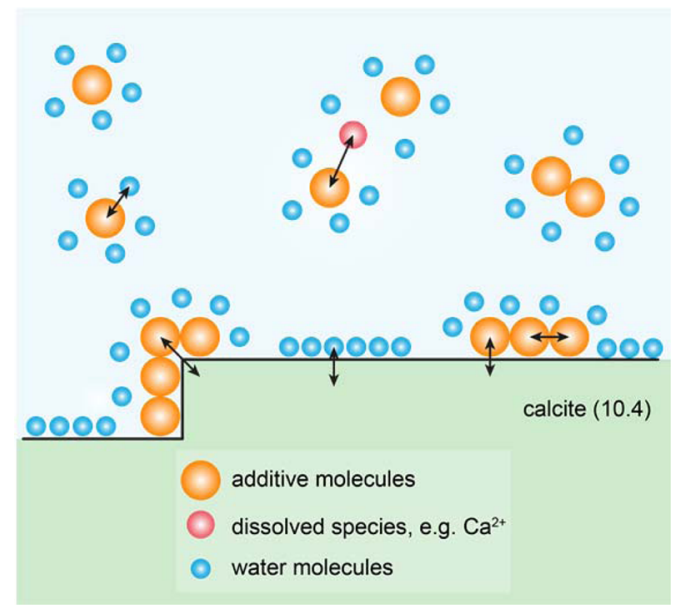

Figure 8. Schematic drawing illustrating the major interactions involved. For simplicity, only few water molecules are drawn exemplarily. Several important interactions are indicated by arrows.

possess a hydration shell and can form complexes with the dissolved species, e.g., calcium ions. The surface-being hydrophilic-is covered by hydration layers with the first water layer being strongly bond to the calcium ions. For the molecules to adsorb on the surface (regardless of the position on the surface), therefore, requires breaking the molecule's hydration shell and the water-surface bond. In the case of a water-soluble molecule and a hydrophilic surface, these two processes are typically nonfavored. If reactive sites such as step edges are present on the surface, the molecule-surface interaction can become very strong, effectively dominating over all other interactions. In this case, molecule-induced surface restructuring can occur as molecules can stabilize otherwise nonfavored step edges.

When molecules adsorb on the defect-free terrace as in the case of a self-assembled structure, in contrast, the moleculesurface interaction is typically weaker than for adsorption at step edges. Still, it needs to be strong enough for replacing the adsorbed water molecules. Furthermore, an ordered selfassembled structure requires an intermolecular interaction that is of the same order of magnitude as the moleculesurface interaction. In essence, the formation of a selfassembled structure on the terrace is, therefore, limited to very special conditions.

Thus, the precise control of the molecule's properties required for achieving a self-assembled structure might be explained by the fact that self-assembly is based on a subtle balance between molecule-surface and molecule-molecule interactions. This balance might easily be perturbed by a small conformational change only. Additive-induced reconstruction, on the other hand, is dominated by molecule-surface interactions, which can be more insensitive to variations in the molecular structure and apparently also deprotonation state.

\section{SUMMARY AND CONCLUSION}

The impact of a class of Eriochrome azo dyes on the calcite (10.4)-water interface is studied using high-resolution FMAFM operated in water. A characteristic surface restructuring is observed during calcite dissolution in the presence of the additives, irrespective of the specific dye structure, conformation, and deprotonation state. The restructuring appears to be a result of specific step edge decoration by the molecules, favoring the nonpolar, acute step edges and the polar step edge along the [010] direction. In sharp contrast to this prevalent surface restructuring, self-assembly of molecular rows on the terrace of the (10.4) surface is observed for one Eriochrome dye only and limited to a very narrow $\mathrm{pH}$ range around a $\mathrm{pH}$ value of 3.6. Our results indicate that, while molecular selfassembly appears to require precise control over the molecular structure and deprotonation state, the surface restructuring mechanism is a more general property of the Eriochrome dyes that is robust against variations in the molecular structure and deprotonation state. This finding might be explained by the fact that molecular self-assembly is based on a subtle balance of molecule-molecule and molecule-surface interactions, while surface restructuring will be dominated by molecule-surface interactions with less impact of the molecule-molecule interaction. This insight contributes to attaining rational control in additive-induced surface modifications.

\section{ASSOCIATED CONTENT}

\section{S Supporting Information}

The Supporting Information is available free of charge on the ACS Publications website at DOI: 10.1021/acs.langmuir.6b02685.

Further information on molecules used (PDF)

\section{AUTHOR INFORMATION}

\section{Corresponding Author}

*E-mail: kuehnle@uni-mainz.de.

\section{Author Contributions}

The manuscript was written through contributions of all authors. All authors have given approval to the final version of the manuscript.

\section{Notes}

The authors declare no competing financial interest.

\section{ACKNOWLEDGMENTS}

Financial support by the German Research Foundation through project KU1980/7-1 is gratefully acknowledged.

\section{ABBREVIATIONS}

EBT, Eriochrome Black T; EBA, Eriochrome Black A; FM$\mathrm{AFM}$, frequency modulation atomic force microscopy

\section{REFERENCES}

(1) Brown, G. E., Jr. Surface science - How minerals react with water. Science 2001, 294 (5540), 67-69.

(2) Putnis, A. Why Mineral Interfaces Matter. Science 2014, 343 (6178), 1441-1442.

(3) Ruiz-Agudo, E.; Putnis, C. V.; Putnis, A. Coupled dissolution and precipitation at mineral-fluid interfaces. Chem. Geol. 2014, 383, 132146.

(4) Mann, S.; Archibald, D. D.; Didymus, J. M.; Douglas, T.; Heywood, B. R.; Meldrum, F. C.; Reeves, N. J. Crystallization at 
Inorganic-organic Interfaces: Biominerals and Biomimetic Synthesis. Science 1993, 261 (5126), 1286-1292.

(5) Xu, A.-W.; Ma, Y.; Cölfen, H. Biomimetic mineralization. J. Mater. Chem. 2007, 17 (5), 415-449.

(6) Cölfen, H. Biomineralization: A crystal-clear view. Nat. Mater. 2010, 9 (12), 960-961.

(7) Song, R.-Q.; Cölfen, H. Additive controlled crystallization. CrystEngComm 2011, 13 (5), 1249-1276.

(8) Rieger, J.; Frechen, T.; Cox, G.; Heckmann, W.; Schmidt, C.; Thieme, J. Precursor structures in the crystallization/precipitation processes of $\mathrm{CaCO}_{3}$ and control of particle formation by polyelectrolytes. Faraday Discuss. 2007, 136, 265-277.

(9) Rieger, J.; Kellermeier, M.; Nicoleau, L. Formation of Nanoparticles and Nanostructures-An Industrial Perspective on CaCO3, Cement, and Polymers. Angew. Chem., Int. Ed. 2014, 53 (46), 12380-12396.

(10) Stipp, S. L. S.; Eggleston, C. M.; Nielsen, B. S. Calcite SurfaceStructure Observed at Microtopographic and Molecular Scales with Atomic-Force Microscopy (AFM). Geochim. Cosmochim. Acta 1994, 58 (14), 3023-3033.

(11) Orme, C. A.; Noy, A.; Wierzbicki, A.; McBride, M. T.; Grantham, M.; Teng, H. H.; Dove, P. M.; DeYoreo, J. J. Formation of chiral morphologies through selective binding of amino acids to calcite surface steps. Nature 2001, 411, 775-779.

(12) Kristensen, R.; Stipp, S. L. S.; Refson, K. Modeling steps and kinks on the surface of calcite. J. Chem. Phys. 2004, 121 (17), 85118523.

(13) Harstad, A. O.; Stipp, S. L. S. Calcite dissolution: Effects of trace cations naturally present in Iceland spar calcites. Geochim. Cosmochim. Acta 2007, 71 (1), 56-70.

(14) Rode, S.; Oyabu, N.; Kobayashi, K.; Yamada, H.; Kühnle, A. True Atomic-Resolution Imaging of (1014) Calcite in Aqueous Solution by Frequency Modulation Atomic Force Microscopy. Langmuir 2009, 25 (5), 2850-2853.

(15) Henriksen, K.; Stipp, S. L. S. Controlling Biomineralization: The Effect of Solution Composition on Coccolith Polysaccharide Functionality. Cryst. Growth Des. 2009, 9 (5), 2088-2097.

(16) Sand, K. K.; Yang, M.; Makovicky, E.; Cooke, D. J.; Hassenkam, T.; Bechgaard, K.; Stipp, S. L. S. Binding of Ethanol on Calcite: The Role of the $\mathrm{OH}$ Bond and Its Relevance to Biomineralization. Langmuir 2010, 26 (19), 15239-15247.

(17) Pasarin, I. S.; Yang, M.; Bovet, N.; Glyvradal, M.; Nielsen, M. M.; Bohr, J.; Feidenhans'l, R.; Stipp, S. L. S. Molecular Ordering of Ethanol at the Calcite Surface. Langmuir 2012, 28 (5), 2545-2550.

(18) Dietzsch, M.; Barz, M.; Schüler, T.; Klassen, S.; Schreiber, M.; Susewind, M.; Loges, N.; Lang, M.; Hellmann, N.; Fritz, M.; Fischer, K.; Theato, P.; Kühnle, A.; Schmidt, M.; Zentel, R; Tremel, W. PAAPAMPS Copolymers as an Efficient Tool to Control $\mathrm{CaCO}_{3}$ Scale Formation. Langmuir 2013, 29 (9), 3080-3088.

(19) Schreiber, M.; Eckardt, M.; Klassen, S.; Adam, H.; Nalbach, M.; Greifenstein, L.; Kling, F.; Kittelmann, M.; Bechstein, R.; Kühnle, A. How deprotonation changes molecular self-assembly - an AFM study in liquid environment. Soft Matter 2013, 9 (29), 7145-7149.

(20) Marutschke, C.; Walters, D.; Cleveland, J.; Hermes, I.; Bechstein, R.; Kühnle, A. Three-dimensional hydration layer mapping on the (10.4) surface of calcite using amplitude modulation atomic force microscopy. Nanotechnology 2014, 25 (33), 335703.

(21) Momper, R.; Nalbach, M.; Lichtenstein, K.; Bechstein, R.; Kühnle, A. Stabilization of Polar Step Edges on Calcite (10.4) by the Adsorption of Congo Red. Langmuir 2015, 31 (26), 7283-7287.

(22) Schenk, A. S.; Cantaert, B.; Kim, Y.-Y.; Li, Y.; Read, E. S.; Semsarilar, M.; Armes, S. P.; Meldrum, F. C. Systematic Study of the Effects of Polyamines on Calcium Carbonate Precipitation. Chem. Mater. 2014, 26 (8), 2703-2711.

(23) Ricci, M.; Segura, J. J.; Erickson, B. W.; Fantner, G.; Stellacci, F.; Voitchovsky, K. Growth and Dissolution of Calcite in the Presence of Adsorbed Stearic Acid. Langmuir 2015, 31 (27), 7563-7571.

(24) Rae Cho, K.; Kim, Y.-Y.; Yang, P.; Cai, W.; Pan, H.; Kulak, A. N.; Lau, J. L.; Kulshreshtha, P.; Armes, S. P.; Meldrum, F. C.; De
Yoreo, J. J. Direct observation of mineral-organic composite formation reveals occlusion mechanism. Nat. Commun. 2016, 7, 10187.

(25) Nelea, V.; Chien, Y.-C.; Paquette, J.; McKee, M. D. Effects of Full-Length Phosphorylated Osteopontin and Constituent Acidic Peptides and Amino Acids on Calcite Dissolution. Cryst. Growth Des. 2014, 14 (3), 979-987.

(26) Hofmann, S.; Voitchovsky, K.; Spijker, P.; Schmidt, M.; Stumpf, $\mathrm{T}$. Visualising the molecular alteration of the calcite (104) - water interface by sodium nitrate. Sci. Rep. 2016, 6, 21576.

(27) Wang, L.; Qin, L.; Putnis, C. V.; Ruiz-Agudo, E.; King, H. E.; Putnis, A. Visualizing Organophosphate Precipitation at the CalciteWater Interface by in Situ Atomic-Force Microscopy. Environ. Sci. Technol. 2016, 50 (1), 259-268.

(28) Hendley, C. T.; Tao, J.; Kunitake, J. A. M. R.; De Yoreo, J. J.; Estroff, L. A. Microscopy techniques for investigating the control of organic constituents on biomineralization. MRS Bull. 2015, 40 (6), $480-489$.

(29) Fukuma, T.; Ueda, Y.; Yoshioka, S.; Asakawa, H. Atomic-Scale Distribution of Water Molecules at the Mica-Water Interface Visualized by Three-Dimensional Scanning Force Microscopy. Phys. Rev. Lett. 2010, 104 (1), 016101.

(30) Imada, H.; Kimura, K.; Onishi, H. Water and 2-Propanol Structured on Calcite (104) Probed by Frequency-Modulation Atomic Force Microscopy. Langmuir 2013, 29 (34), 10744-10751.

(31) Fenter, P.; Kerisit, S.; Raiteri, P.; Gale, J. D. Is the CalciteWater Interface Understood? Direct Comparisons of Molecular Dynamics Simulations with Specular X-ray Reflectivity Data. J. Phys. Chem. C 2013, 117 (10), 5028-5042.

(32) Sand, K. K.; Pedersen, C. S.; Sjoberg, S.; Nielsen, J. W.; Makovicky, E.; Stipp, S. L. S. Biomineralization: Long-Term Effectiveness of Polysaccharides on the Growth and Dissolution of Calcite. Cryst. Growth Des. 2014, 14 (11), 5486-5494.

(33) We note that the term "self-assembly" is usually used for equilibrium structures while "self-organization" is used for kinetically trapped structures. As it can be far from trivial to evaluate whether a given structure is the equilibrium structure, we decided to use the term "self-assembly" regardless of whether it is in equilibrium or not.

(34) Schwarzenbach, G.; Biedermann, W. Komplexone X. Erdalkalikomplexe von o, o'-Dioxyazofarbstoffen. Helv. Chim. Acta 1948, 31, 678-687.

(35) Diehl, H.; Ellingbee, J. Azo Dyes as Indicators for Calcium and Magnesium. Anal. Chem. 1960, 32 (9), 1120-1123.

(36) Schwarzenbach, G.; Biedermann, W. Die komplexometrische Titration der Erdalkalien und einiger anderer Metalle mit Eriochromschwarz T. Chimia 1948, 2, 56-59.

(37) Masoud, M. S.; Hammud, H. H.; Beidas, H. Dissociation constants of eriochrome black $\mathrm{T}$ and eriochrome blue black $\mathrm{RC}$ indicators and the formation constants of their complexes with $\mathrm{Fe}(\mathrm{III})$, $\mathrm{Co}(\mathrm{II}), \mathrm{Ni}(\mathrm{II}), \mathrm{Cu}(\mathrm{II}), \mathrm{Zn}(\mathrm{II}), \mathrm{Cd}(\mathrm{II}), \mathrm{Hg}(\mathrm{II})$, and $\mathrm{Pb}(\mathrm{II})$, under different temperatures and in presence of different solvents. Thermochim. Acta 2002, 381 (2), 119-131.

(38) Rode, S.; Stark, R.; Lübbe, J.; Tröger, L.; Schütte, J.; Umeda, K.; Kobayashi, K.; Yamada, H.; Kühnle, A. Modification of a commercial atomic force microscopy for low-noise, high-resolution frequencymodulation imaging in liquid environment. Rev. Sci. Instrum. 2011, 82 (7), 073703.

(39) Schäffer, T. E.; Cleveland, J. P.; Ohnesorge, F.; Walters, D.; Hansma, P. K. Studies of vibrating atomic force microscope cantilevers in liquid. J. Appl. Phys. 1996, 80 (7), 3622-3627.

(40) Adam, H.; Rode, S.; Schreiber, M.; Kobayashi, K.; Yamada, H.; Kühnle, A. Photothermal excitation setup for a modified commercial atomic force microscope. Rev. Sci. Instrum. 2014, 85 (2), 023703.

(41) Britt, D. W.; Hlady, V. In-situ atomic force microscope imaging of calcite etch pit morphology changes in undersaturated and 1hydroxyethylidene-1,1-diphosphonic acid poisoned solutions. Langmuir 1997, 13 (7), 1873-1876.

(42) Liang, Y.; Baer, D. R.; Lea, A. S. Dissolution of $\mathrm{CaCO}_{3}(1014)$ Surface. MRS Online Proc. Libr. 1994, 355, 409. 
(43) Park, N.-S.; Kim, M.-W.; Langford, S. C.; Dickinson, J. T. Tribological Enhancement of $\mathrm{CaCO}_{3}$ Dissolution during Scanning Force Microscopy. Langmuir 1996, 12 (19), 4599-4604.

(44) Sagaster, H.-R.; Röbisch, G.; Mehlhorn, A. Untersuchungen zur Tautomerie von o,o'-Dihydroxy-azofarbstoffen. J. Prakt. Chem. 1987, 329 (6), 1045-1051. 